\title{
Changes in breast cancer biomarkers in the IGF1R/PI3K pathway in recurrent breast cancer after tamoxifen treatment
}

\author{
S C Drury ${ }^{1,2}$, S Detre $^{2}$, A Leary $_{1}^{3}$, J Salter ${ }^{1,2}$, J Reis-Filho $^{4}$, V Barbashina ${ }^{4}$, \\ C Marchio ${ }^{5}$, E Lopez-Knowles ${ }^{1}, Z$ Ghazoui ${ }^{1}, K^{\prime}$ Habben $^{6}$, S Arbogast ${ }^{6}$, \\ $S$ Johnston ${ }^{7}$ and $M$ Dowsett ${ }^{1,2}$
}

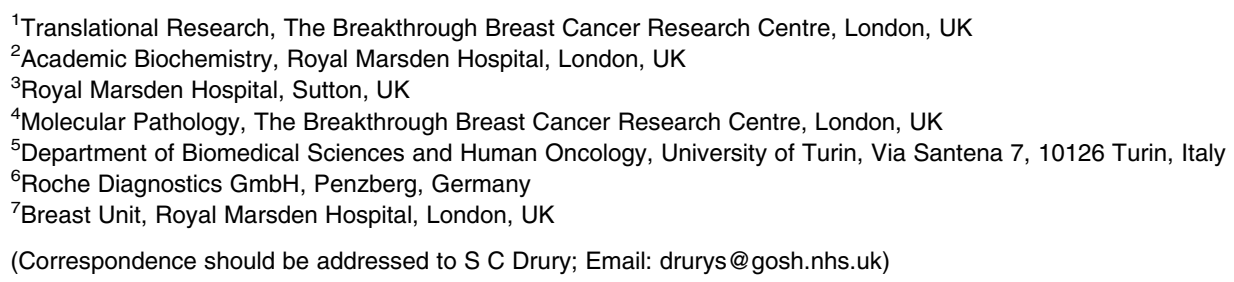

\begin{abstract}
Development of resistance to the antioestrogen tamoxifen occurs in a large proportion of patients with oestrogen receptor-positive $(\mathrm{ER}+)$ breast cancer and is an important clinical challenge. While loss of ER occurs in c. $20 \%$ of tamoxifen-resistant tumours, this cannot be the sole explanation for tamoxifen treatment failure. PI3K pathway activation, including by insulin-like growth factor receptor 1 (IGF1R), has been implicated in some resistance models. The primary aim was to determine whether evidence exists in clinical breast cancer for a role of IGF1R and/or the PI3K pathway, in acquisition of resistance to tamoxifen. Invasive primary and recurrent tamoxifen-resistant tumours from the same patient $(n=77)$ were assessed for changes in ER, progesterone receptor (PgR), human epidermal growth factor receptor 2 (HER2), IGF1R, stathmin, PTEN expression and PIK3CA mutations where possible. ER and PgR levels were significantly reduced at recurrence with 22 and $45 \%$, respectively, showing negative status at this time. Acquisition of HER2 overexpression occurred in $6 \%$ of cases. IGF1R expression was significantly reduced in both $\mathrm{ER}+$ and $\mathrm{ER}-$ recurrences and stathmin levels increased. A positive association between stathmin and IGF1R emerged in recurrent samples, despite their opposing relationships with ER, suggesting some coalescence of their activities may be acquired. The data confirm loss of ER and PgR and gain of HER2 in some tamoxifen-resistant tumours. There is no evidence for IGF1R gain in tamoxifen resistance; increases in stathmin levels suggest that activation of the PI3K pathway may have contributed, but PTEN loss and PIK3CA hotspot mutations were relatively rare.
\end{abstract}

Endocrine-Related Cancer (2011) 18 565-577

\section{Introduction}

Until recently, tamoxifen has been the gold standard endocrine treatment for oestrogen receptor-positive $(\mathrm{ER}+)$ breast cancer and despite the advent of aromatase inhibitors, it continues to be an important therapeutic option. Tamoxifen use was attributed to a $40 \%$ reduction in recurrent and contralateral disease and can be used as a prophylactic (Cuzick et al. 2007). However, $\sim 40 \%$ of women receiving tamoxifen as adjuvant therapy will recur (Early Breast Cancer Trialists' Collaborative Group 1998) and almost all patients with metastatic disease develop resistance.

The primary mode of action of tamoxifen is by competing with oestrogen for $\mathrm{ER} \alpha$, inhibiting the stimulatory effect of oestrogen for tumour growth. While preclinical evidence for other mechanisms has been produced, there is very little clinical evidence to support these. The benefit from tamoxifen is restricted 
to ER+ tumours (Early Breast Cancer Trialists' Collaborative Group 1988) other than the small group of ER - progesterone receptor-positive $(\mathrm{PgR}+)$ tumours that may be mainly due to false negative ER diagnosis. Our earlier work indicated that approximately one-fifth of recurrent tumours following tamoxifen treatment of ER + primary disease, show ER negativity (Johnston et al. 1995, Gutierrez et al. 2005). So while positive ER status is a key determinant of response to tamoxifen, loss of ER can only explain a minority of acquired tamoxifen resistance.

Crosstalk between ER and growth factor receptor pathways has been well documented (Hutcheson et al. 2003, Nicholson et al. 2005). ER can be phosphorylated by MAP kinases downstream of the human epidermal growth factor receptor 2 (HER2) signalling pathway, which can lead to ligand-independent activation (Bunone et al. 1996) while tamoxifenresistant cells can switch their cell growth dependence between HER2 and ER pathways (Pancholi et al. 2008). In our earlier clinical studies, we found that amplification of HER2 occurred in the tamoxifenresistant recurrence of $11 \%$ of patients who had a HER2 - primary (Gutierrez et al. 2005). However, other growth factor receptors have been implicated in the acquisition of tamoxifen resistance including epidermal growth factor (EGFR), HER3 and insulinlike growth factor receptor 1 (IGF1R). In this study, we have focused on aspects of the IGF1R pathway.

IGF1 is a mitogen for human breast cancer cells in vitro, acting primarily via a specific cell surface glycoprotein, IGF1R, especially in the presence of oestradiol $\left(\mathrm{E}_{2}\right)$, with which it synergises (Dupont \& Le Roith 2001). Breast cancer cell models have shown mixed changes in IGF1R expression with tamoxifen treatment. IGFIR mRNA levels are increased by $\mathrm{E}_{2}$ in MCF7 breast cancer cells (Stewart et al. 1990). No change was observed in MCF7 cells treated with tamoxifen (Guvakova \& Surmacz 1997, Chan et al. 2001), but tamoxifen-resistant cells showed reduced IGF1R (Frogne et al. 2005).

IGF binding induces IGF1R autophosphorylation, with p-IGF1R phosphorylating IRS1, IRS2 and Shc, activating transduction pathways such as PI3K and Ras/Raf/MAPK (Riedemann \& Macaulay 2006). In addition, IGF1R physically associates with $\mathrm{ER} \alpha$ and this leads to activation of IGF1R and the downstream ERK1/2 MAPK pathways. Tamoxifen-resistant MCF7 xenograft models, have higher activated p-IGF1R as opposed to tamoxifen-sensitive models (Massarweh et al. 2008) and clinically, p-IGF1R is associated with poor survival in invasive breast cancer samples (Law et al. 2008).
The PI3K pathway is an important driver of proliferation and cell survival, most notably in cells that are responding to growth factor receptor engagement, such as IGF1R, where binding to ligand causes phosphorylation of $\mathrm{PIP}_{2}$ to $\mathrm{PIP}_{3}$. This recruits PDK1, which phosphorylates and activates Akt, perpetuating downstream signalling. PTEN negatively regulates PI3K by dephosphorylating PIP $_{3}$. While measurement of each of these components may allow derivation of the individual activities in tamoxifen-resistant breast cancer, stathmin, a regulator of microtubule dynamics, has been identified as a marker of PTEN mutation or loss and PI3K activation in breast cancer (Saal et al. 2007), that acts to integrate the upstream components. Stathmin was found to be an accurate immunohistochemical (IHC) marker of the gene expression signature for IHC-detectable PTEN loss.

Approximately, $80 \%$ of PIK3CA mutations occur in three hotspots resulting in single amino acid substitutions; E545K and E542K in the helical domain (exon 9) and H1047R in the kinase domain (exon 20). A recent study of 590 breast cancers showed mutations in one-third of cases (Kalinsky et al. 2009). Mutations were associated with hormone receptor positivity, absence of HER2, low tumour grade and stage and lymph node negativity. An earlier study of 157 hormone receptor-positive tumours suggested that PIK3CA mutations did not have an effect on outcome after tamoxifen therapy (Stemke-Hale et al. 2008).

The primary aim of this study was to determine whether there was evidence for a role of IGF1R and/or the PTEN/PI3K pathway in acquired resistance to tamoxifen by assessing the expression of IGF1R, stathmin and PTEN in paired breast cancer biopsies before and after development of tamoxifen resistance, in addition to the assessment of hotspot mutations in PIK3CA. Any changes in these markers were related to the changes in the expression of steroid receptors and HER2 that we have previously reported in part of this sample set (Johnston et al. 1995, Gutierrez et al. 2005), since the expression of these key parameters markedly affects the interpretation of other changes in phenotype.

\section{Patients and methods}

\section{Patients}

Seventy-seven patients diagnosed between 1981 and 2004 at the Royal Marsden Hospital were identified, who had tissue available from both primary invasive tumour and subsequent invasive recurrence following adjuvant tamoxifen treatment. This included 51 patients from an earlier report on steroid receptor and 
HER2, but not IGF1R or stathmin (Gutierrez et al. 2005). Previously untreated patients who received tamoxifen for at least 6 months as adjuvant therapy and who had a recurrence at least 6 months after their primary occurrence were classed as tamoxifen-resistant. Patients whose recurrence occurred 6 months after the primary were not included as they were classed as de novo resistant. The time to recurrence was defined as time (in months) between surgery for the primary disease and surgery for the recurrent disease. No patients received neoadjuvant therapy for their primary disease, thus date of surgery was close to the date of presentation. Owing to the era during which patients were treated, there was a group $(n=12)$ of ERprimaries treated with tamoxifen. These ER - cases were used only to assess the relationship of each marker (PgR, HER2, IGF1R and stathmin) with ER and the main focus was on those 55 paired patients with $\mathrm{ER}+$ primary disease. Menopausal status was not rigorously recorded but 28 of these patients were under the age of 55. Patients were included irrespective of whether they received chemotherapy, or their being on tamoxifen at the time of recurrence. This latter circumstance was considered separately in the data analysis.

\section{Tissue microarray and immunohistochemistry}

Sections $(4 \mu \mathrm{m})$ of primary and recurrent tumours were cut and stained by hematoxylin and eosin (H\&E) and used to mark areas of invasive tumour for core selection. Tissue microarrays were constructed in triplicate with $0.6 \mathrm{~mm}$ cores. Sections $(4 \mu \mathrm{m})$ were stained for ER, HER2, IGF1R, stathmin and PTEN. In addition, $\mathrm{PgR}$ was stained on whole sections, due to the heterogeneous expression of this marker (Quinn et al. 2008). Antigen retrieval for $\mathrm{ER}$ and $\mathrm{PgR}$ was by microwave for $5 \mathrm{~min}$ at full power $(900 \mathrm{~W})$ in citrate buffer $\mathrm{pH}$ 6.0. Antibody for ER (6F11, Vector Labs, Orton Southgate, Peterborough, UK) was applied at 1/40 dilution and PgR (321, Vector Labs) 1/100. HER2 was detected by HercepTest according to the manufacturer's instructions. Immunohistochemistry using these antibodies has been widely published (Dowsett 2006, Dowsett et al. 2008). IGF1R (G11, Ventana, Roche Diagnostics, Penzberg, Germany) was stained using the Ventana Benchmark XT at Roche, with antigen retrieval by standard $\mathrm{CC} 1$ recovery conditions and $1.7 \mu \mathrm{g} / \mathrm{ml}$ concentration. Validation of this antibody is shown in Supplementary Figure 1, see section on supplementary data given at the end of this article. Stathmin (Cell Signalling, Danvers, MA, USA) was detected following antigen retrieval for $10 \mathrm{~min}$ in
Target Retrieval Solution pH 9.0 (Dako, Ely, Cambridgeshire, UK) heated at $97{ }^{\circ} \mathrm{C}$ by water bath, followed by application of 1/100 antibody and use of this antibody has been previously published (Saal et al. 2007). PTEN was detected using clone 6H2.1 (Dako M3627), with antigen retrieval by microwave in citrate buffer $\mathrm{pH} 9.0$ for $18 \mathrm{~min}$ and cooling for 20 min. Visualisation was with Vector ABC. HER2 copy number was determined by fluorescent in situ hybridisation (FISH) with the Pathvysion Her2 DNA probe kit (Vysis, Abbott Molecular, IL, USA).

Nuclear ER and PgR were scored using the histoscore (H-score) and were classed as positive if $\mathrm{H}$-score was $>1$ (equivalent Allred score $\geq 3$ ) and $>20$ respectively. Correlation between two independent scorers for ER and PgR, was very good (Pearson $r=0.93 ; P=0.0001$ and $r=0.95 ; P<0.0001)$ respectively $(n=10)$. HER2 was scored positive if the HercepTest was $3+$ or $2+$ and FISH-positive (ratio of $H E R 2 / C E P 17 \geq 2.0$ ). IGF1R was scored by assigning a score for membrane intensity, ranging from 0 to 3 in 0.5 increments. This was a modification of the approach to scoring with the HercepTest, with 0.5 increments of intensity introduced to increase sensitivity and to represent those cases that would otherwise be considered ambiguous. A score of 1.5, for example represents a staining which one might consider a one or two. Weighted Kappa coefficient for IGF1R between two scorers was good (0.65). Cytoplasmic stathmin was described using the modified quick score (Detre et al. 1995) where an overall intensity of $0,1,2$ or 3 was assigned and multiplied by a factor representing the percentage of cells staining brown (where $0 \%=0$, $1-4 \%=1, \quad 5-19 \%=2, \quad 20-39 \%=3,40-59 \%=4$, $60-79 \%=5$ and $80-100 \%=6$ ). Correlation for this marker was also good between scorers (Pearson $r=0.97$; $P=0.001)$. Nuclear and cytoplasmic PTEN was scored simultaneously by two pathologists, with normal cells taken as an internal control; absence of staining in tumour cells relative to control was scored as zero, staining of a similar intensity to control as one and higher than the control as two (Sakr et al. 2010). Samples were excluded if there were no normal cells present to act as an internal control.

\section{DNA extraction}

Sections $(3 \times 8 \mu \mathrm{m})$ were microdissected to enrich for tumour content and DNA extracted using a modified version of the DNeasy Tissue kit (Qiagen). Briefly, following microdissection, sections were treated overnight with $1 \mathrm{M}$ sodium thiocyanate and washed twice with PBS. Tumour was scraped into $180 \mu \mathrm{l}$ of buffer 
Table 1 Demographics of patients recurring after treatment with adjuvant tamoxifen ${ }^{\mathrm{a}}$

\begin{tabular}{|c|c|c|}
\hline Feature & $\begin{array}{l}\text { All patients } \\
(n=77)\end{array}$ & $\begin{array}{l}\text { ER }+ \text { primary } \\
\text { paired patients } \\
(n=55)\end{array}$ \\
\hline Age at diagnosis & $\begin{array}{l}55 \text { years } \\
\quad(28-81 \text { years })\end{array}$ & $\begin{array}{l}54 \text { years } \\
\quad(28-86 \text { years })\end{array}$ \\
\hline $\begin{array}{l}\text { Duration of } \\
\text { tamoxifen }\end{array}$ & $\begin{array}{l}27 \text { months } \\
(6-84 \text { months })^{\mathrm{b}}\end{array}$ & $\begin{array}{l}36 \text { months } \\
\text { (6-84 months) }\end{array}$ \\
\hline $\begin{array}{l}\text { Time to recurrence } \\
\text { (TTR) }\end{array}$ & $\begin{array}{l}30 \text { months } \\
\text { (6-146 months) }\end{array}$ & $\begin{array}{l}43 \text { months } \\
\text { (6-146 months) }\end{array}$ \\
\hline Tumour size & $\begin{array}{l}20 \mathrm{~mm} \\
\quad(3-70 \mathrm{~mm})^{\mathrm{c}}\end{array}$ & $\begin{array}{l}20 \mathrm{~mm} \\
\quad(7-70 \mathrm{~mm})^{\mathrm{d}}\end{array}$ \\
\hline \multicolumn{3}{|l|}{ Nodes (\%) } \\
\hline Positive & $18(23 \%)$ & $13(24 \%)$ \\
\hline Negative & $15(20 \%)$ & $13(24 \%)$ \\
\hline Unknown & $44(57 \%)$ & $29(52 \%)$ \\
\hline \multicolumn{3}{|l|}{ Grade, $n(\%)$} \\
\hline Grade 1 & $5(7 \%)$ & $3(5 \%)$ \\
\hline Grade 2 & $28(36 \%)$ & $21(38 \%)$ \\
\hline Grade 3 & $12(16 \%)$ & $9(16 \%)$ \\
\hline Unknown & $32(42 \%)$ & $22(40 \%)$ \\
\hline \multicolumn{3}{|c|}{ Adjuvant treatment, $n(\%)$} \\
\hline Tamoxifen & $77(100 \%)$ & $55(100 \%)$ \\
\hline Radiotherapy & $14(18 \%)$ & $11(20 \%)$ \\
\hline Chemotherapy & $11(14 \%)$ & $8(15 \%)$ \\
\hline $\begin{array}{l}\text { Radiotherapy and } \\
\text { chemotherapy }\end{array}$ & $12(16 \%)$ & $4(7 \%)$ \\
\hline
\end{tabular}

${ }^{\mathrm{a} C}$ Clinicopathological data were not available for all samples; ${ }^{\mathrm{b}} n=76 ;{ }^{\mathrm{c}} n=50 ;{ }^{\mathrm{d}} n=36$.

RLT from the kit and $20 \mu$ proteinase $\mathrm{K}$ added, then the manufacturer's protocol continued. DNA was quantified by PicoGreen (Invitrogen, Paisley, UK).

\section{PIK3CA sequencing}

PCR with primers spanning the hotspot mutation regions of exons 9 and 20 PIK3CA gene were performed with $20 \mathrm{ng}$ of DNA (exon $9 \mathrm{~F}$ : CTGTAAATCATCTGTGAAT and R: ATTTTAGCACTTACCTGTGAC and exon 20F: CAATCTTTTGATGACATTGC and R: TGGAATCCAGAGTGAGCTTT), under the following conditions; $94{ }^{\circ} \mathrm{C} 10 \mathrm{~min}\left(94{ }^{\circ} \mathrm{C} 30 \mathrm{~s}, 50{ }^{\circ} \mathrm{C}\right.$ $30 \mathrm{~s}$ and $\left.72{ }^{\circ} \mathrm{C} 30 \mathrm{~s}\right) \times 40,72^{\circ} \mathrm{C} 10 \mathrm{~min}$. PCR products were purified and sequenced on an $\mathrm{ABI} 3130 \times 1$ with the Big Dye 1.1 kit (Applied Biosystems, Warrington, Cheshire, UK) as per manufacturer's instructions. Derived sequences were blasted against the known gene sequence and any observed mutations confirmed by an independent PCR and sequencing with the reverse primer.

\section{Data analysis}

GraphPad Prism (GraphPad Software, La Jolla, CA, USA) was used to calculate all statistics. To assess differences between paired primary and recurrence, Wilcoxon matched-pairs test was used. Differences between unpaired groups were measured by the MannWhitney $U$ test and Spearman rank was used to determine correlations of datasets. Significance was taken as $P \leq 0.05$.

Clustering analyses was performed by data from all biomarkers (ER, PGR, IGF1R, STMN1, HER2, PTEN and PIK3CA). Data for HER2, PTEN and PIK3CA were converted from - and + to binary data ( 0 and 1 respectively). Missing data has been left as missing. Data for ER, PGR, IGF1R and STMN1 have been normalised so that the scale of these data is from 0 to 1 .

\section{Results}

\section{Patient demographic}

Patient demographics are listed in Table 1. Median patient age was 55 years at diagnosis. A median of 27 months of tamoxifen treatment had been received with a median time to recurrence of 30 months. 11 patients had also chemotherapy between their primary and recurrence date, 14 had radiotherapy and 12 had both chemotherapy and radiotherapy.

Eleven (20\%) ER + primary patients were not on tamoxifen at the time of recurrence and had finished endocrine therapy a median of 33 months before (range 17-66 months). These patients had received a median of 60 months tamoxifen and had a median time to recurrence of 90 months. Cases recurring on tamoxifen were therefore also analysed separately, although sample numbers were consequently reduced.

\section{Relationship of biomarkers with ER}

Expression of PgR, HER2, IGF1R and stathmin was significantly different between ER + and ER primary tumours (Table 2): PgR and IGF1R were higher in ER + tumours while HER2 and stathmin

Table 2 Biomarker immuno score in primary tumours according to oestrogen receptor (ER) status (median). There was a significant association with ER status with the exception of PTEN. See methods section for scoring methods

\begin{tabular}{|c|c|c|c|c|}
\hline \multirow[b]{2}{*}{ Marker } & \multirow{2}{*}{$\begin{array}{l}\text { Scoring } \\
\text { method }\end{array}$} & \multicolumn{3}{|c|}{ Score $(n)$} \\
\hline & & ER + & ER- & $P$ value \\
\hline $\mathrm{PgR}$ & H-score & $105.1(51)$ & $19.1(12)$ & $<0.0001$ \\
\hline HER2 & Positive (\%) & $13 \%(49)$ & $57 \%(14)$ & 0.0002 \\
\hline IGF1R & $\begin{array}{l}\text { Membrane } \\
\text { intensity }\end{array}$ & $1.5(60)$ & $0.8(16)$ & 0.0001 \\
\hline Stathmin & Q-score & $4.8(48)$ & $8.1(10)$ & 0.0075 \\
\hline PTEN & Positive (\%) & $73 \%(40)$ & $75 \%(12)$ & 0.1349 \\
\hline
\end{tabular}


Table 3 Correlation of markers with oestrogen receptor $(E R)$ in $\mathrm{ER}+$ primary tumours and their matched recurrence. The only significant association with ER is progesterone receptor $(\mathrm{PgR})$ in the recurrence sample

\begin{tabular}{lrrrrr}
\hline & \multicolumn{2}{c}{ Primary } & & \multicolumn{2}{c}{ Recurrence } \\
\cline { 2 - 3 } \cline { 5 - 6 } Marker $(n)$ & Spearman $\boldsymbol{r}$ & $\boldsymbol{P}$ value & & Spearman $\boldsymbol{r}$ & $\boldsymbol{P}$ value \\
\hline PgR (54) & -0.12 & 0.382 & & 0.36 & 0.008 \\
HER2 (48) & -0.18 & 0.213 & & 0.08 & 0.598 \\
IGF1R (49) & 0.00 & 1.000 & & 0.24 & 0.103 \\
Stathmin (49) & -0.17 & 0.254 & & 0.13 & 0.391 \\
\hline
\end{tabular}

were lower. This extended to a quantitative relationship between ER and $\operatorname{PgR}(r=0.30 ; P=0.013)$, IGF1R $(r=0.34 ; P=0.007)$ and stathmin $(r=-0.45$; $P=0.0003)$. However, there was no significant difference in incidence of PTEN positivity between $\mathrm{ER}+$ and ER - tumours.

Considering only ER + primary tumours, there was no quantitative correlation between ER and PgR, HER2, IGF1R or stathmin (Table 3).

However, there was a significant positive correlation between ER and $\mathrm{PgR}$ in the recurrence sample $(r=0.36 ; P=0.008$; Table 3$)$.

Patients with an ER + primary tumour had significantly longer TTR than those with an ERprimary (median 41 (range 6-146) months versus 24 (6-82) months; $P=0.030$ ).

The following data relate to patients with ER+ primary tumours.

\section{Oestrogen receptor}

Twelve of $55(22 \%)$ ER + primaries with a recurrent ER measurement available, recurred as ER - disease (Fig. 1a). Distribution of ER H-scores in the primary sample ranged from 5.0 to 275.0 , with a median of 95.5. ER - disease occurred only in patients who recurred whilst taking tamoxifen. Nineteen of the 43 patients (44\%) with ER + primary and ER + recurrent disease had reduced ER by $\geq 33 \%$ (Fig. 1b) at the time of recurrence, seven (16\%) an increase of $\geq 50 \%$ (Fig. 1d) and in the remaining 17 (40\%) patients any change was within these limits (Fig. 1c). Even in $\mathrm{ER}+$ recurrences, median ER level was significantly lower compared with the same tumours pretreatment (H-score 75.0 (interquartile range (IQR) 17.9-113.0) vs 108.0 (IQR 90.9-130.9) $P=0.005$ ). However, the reduction of ER only occurred in the recurrence of those on tamoxifen (median $\mathrm{H}$-score 108.2 vs 74.5; $P=0.0003)$, not those who recurred after finishing tamoxifen (median H-score 55.2 vs 105.8; $P=\mathrm{ns}$ ).

There was a trend to lower ER levels in the primary tumours that recurred as $\mathrm{ER}-(P=0.071)$ and these patients had significantly reduced TTR compared with those that recurred as ER + (median TTR 51.0 vs 19.5 months; $P=0.002$ ).

However, there was no significant difference of PgR, HER2, IGF1R or stathmin in the primary tumour of patients according to the ER status of the recurrent lesion (Table 4).

\section{Progesterone receptor}

Eleven patients (22\%) had an ER + primary that was $\mathrm{PgR}-$. Levels of $\mathrm{PgR}$ in primary tumours that recurred as ER - were lower than those primary tumours that recurred as ER + (Table 4) and had a shorter TTR (30 vs 42.5 months), but these differences were not significant. Overall, there was a significant reduction of $\mathrm{PgR}$ in recurrent tumours (median $\mathrm{H}$-score pre122.4 versus post- $21.8 ; P<0.0001)$. This was also the case separately in those that remained ER + (median $\mathrm{H}$-score pre- 132.3 versus post- $32.3 ; P=0.004)$ and those which recurred as ER - (median H-score pre- 71.0 versus post- $8.9 ; P=0.001$ ).

There appeared to be a greater reduction of $\mathrm{PgR}$ in tumours that had an ER - (Fig. 2a) or ER low (H-score 1-25; Fig. 2b) recurrence than an ER moderate to high
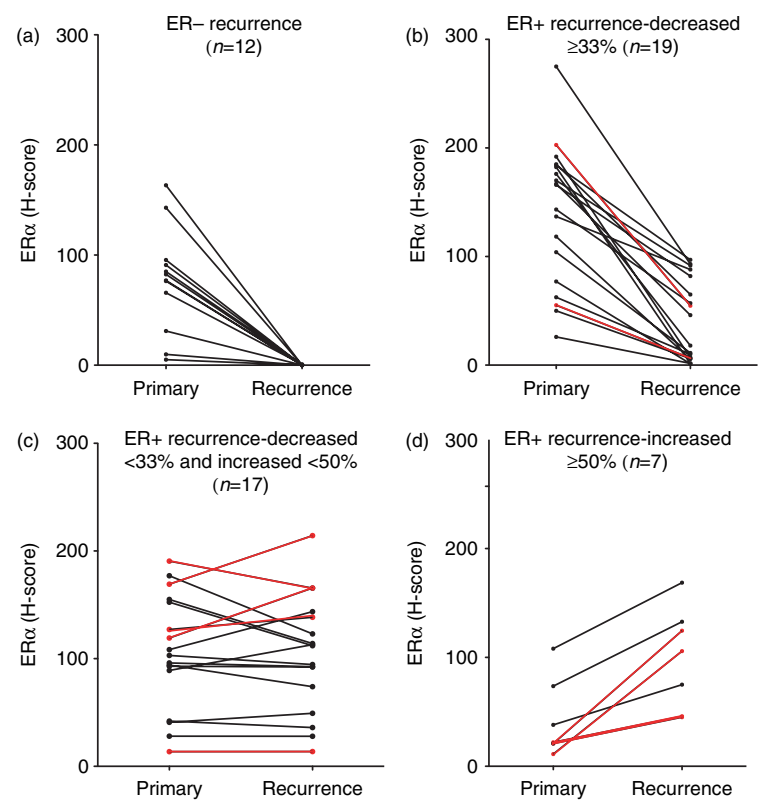

Figure 1 ER expression in primary and tamoxifen-resistant recurrences. ER expression was lost completely in $22 \%$ of recurrences (a). In ER-positive recurrences, ER levels were reduced by more than one-third in $44 \%$ of recurrences (b) and increased by more than half in just seven recurrences (c) ER expression remained relatively consistent (d) in the remaining tumours which had originally presented as $\mathrm{ER}+$. Red lines indicate those patients whose recurrence occurred after completing tamoxifen therapy. 
Table 4 Biomarker immuno score in oestrogen receptorpositive $(E R+)$ primary tumours, according to their recurrent ER status (median)

\begin{tabular}{lllll}
\hline & & \multicolumn{3}{c}{ Score $(n)$} \\
\cline { 3 - 5 } Marker & $\begin{array}{l}\text { Scoring } \\
\text { method }\end{array}$ & $\begin{array}{l}\mathbf{1}^{\circ} \text { of ER }+ \\
\text { recurrence }\end{array}$ & $\begin{array}{l}\mathbf{1}^{\circ} \text { of ER }- \\
\text { recurrence }\end{array}$ & $\boldsymbol{P}$ value \\
\hline ER & H-score & $108.0(43)$ & $79.7(12)$ & 0.071 \\
PgR & H-score & $132.3(39)$ & $71.0(12)$ & 0.418 \\
HER2 & Positive (\%) & $11 \%(36)$ & $10 \%(10)$ & 1.000 \\
IGF1R & Membrane & $1.51(37)$ & $1.75(12)$ & 1.000 \\
Stathmin & intensity & & & \\
PTEN & Poscore & $2.5(37)$ & $5.6(12)$ & 0.121 \\
\hline
\end{tabular}

recurrences (Fig. 2c). PgR status changed in four patients from negative to positive, and this was restricted to tumours with an ER H-score $\geq 25$ at recurrence (Fig. 2c). Patients with an ER $+\mathrm{PgR}+$ primary tumour that recurred as $\mathrm{PgR}+$ had longer TTR than those whose tumour recurred as PgR(49 vs 30 months), but this was not statistically significant.

In those patients recurring whilst taking tamoxifen $(n=43), 28 \%$ had an ER + primary that was $\mathrm{PgR}-$. Overall, there was a significant reduction of $\mathrm{PgR}$ in recurrent tumours $(P=0.0002)$. This was also the case separately in those that remained $\mathrm{ER}+(P=0.014)$ and those which recurred as ER $-(P=0.001)$.

\section{Level of ER in recurrent sample}

ER- $(\mathrm{H}$-score $<1)$
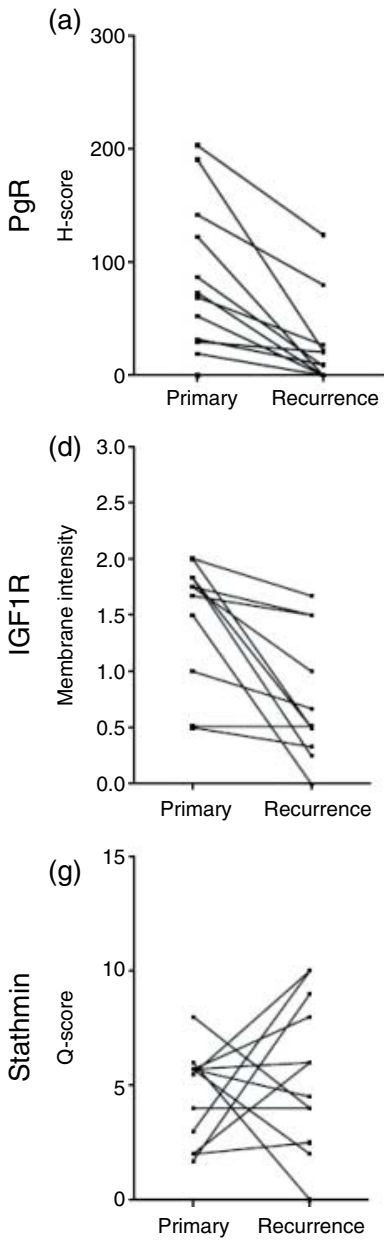
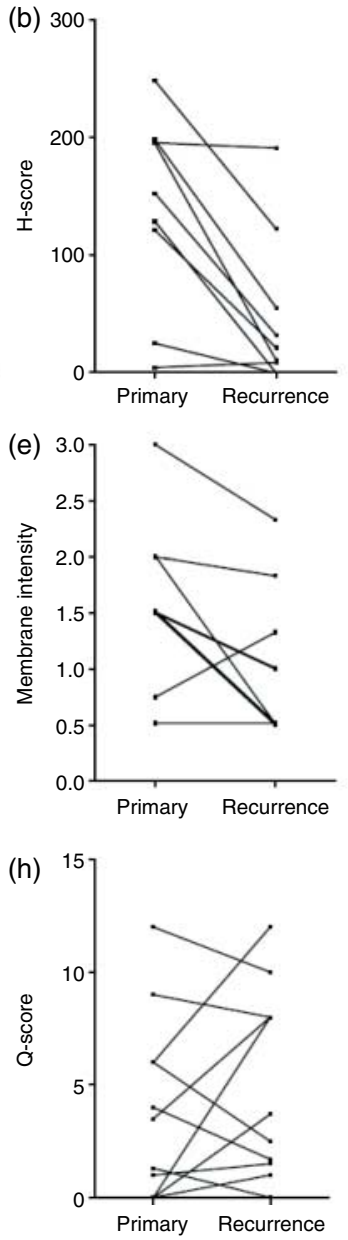

ER $\mathrm{H}$-score $>25$
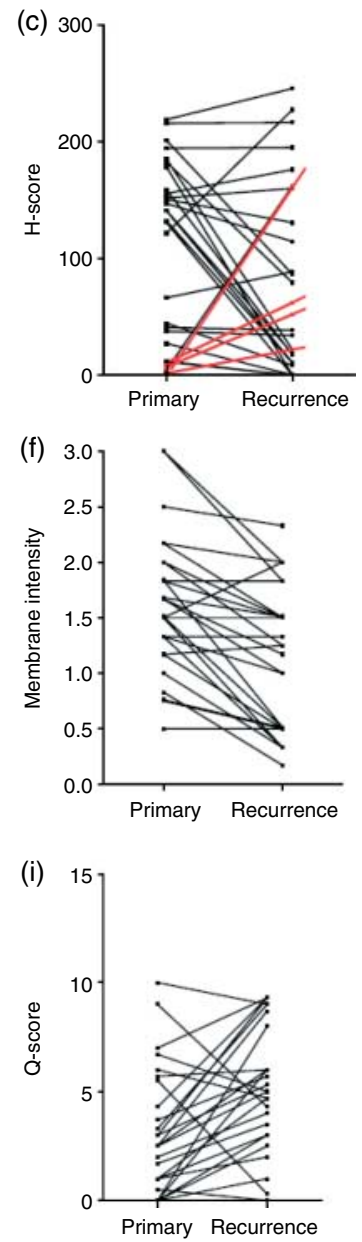

Figure $2 \mathrm{PgR}$, IGF1R and stathmin expression alterations in tamoxifen-resistant recurrences, based on recurrent ER level. Panels a-C show change of $\mathrm{PgR}$ according to recurrent $\mathrm{ER}$ level, with red lines indicating the only four patients in the cohort that switched from $\mathrm{PgR}-$ to $\mathrm{PgR}$, these were confined to the patients with high levels of ER at recurrence. Panels $d-f$ show change of IGF1R. Panels $g-i$ show change of stathmin; $42 \%$ of tumours with an ER - recurrence showed an increase of stathmin $(\mathrm{g})$. This was compared with $45 \%$ of tumours with a low (h) and $73 \%$ of tumours with a high level of ER at recurrence with an increase of stathmin (i). 


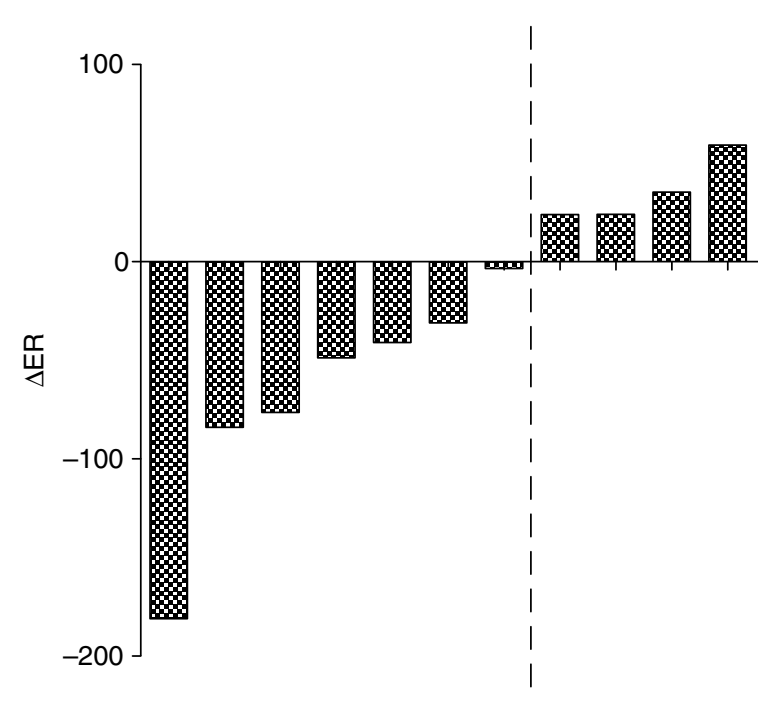

Figure 3 Change of ER in cases with increased HER2 at the time of recurrence. There was a loss of ER in $64 \%$ of cases that had some gain of HER2.

\section{Human epidermal growth factor receptor 2}

HER2 data for paired primary and recurrent tumours was available for $50 \mathrm{ER}+$ primary cases. HER2 positivity occurred at similar frequency $(\sim 10 \%)$ in $\mathrm{ER}+$ primaries that recurred as $\mathrm{ER}+$ or $\mathrm{ER}-$ (Table 4). Of all ER+ primaries, 42 (84\%) were HER 2 - and remained HER2 - in the recurrence.
Four cases were HER2 + and remained so. One case was HER $2+$ in the primary setting and HER2 - at time of recurrence. Only three $(6 \%)$ patients acquired HER2 positivity (as previously reported in the smaller sample set (Gutierrez et al. 2005)); this was associated with loss of ER in one case. When HercepTest scores were assessed, 11 cases showed some increase of HER 2 between primary and recurrence (e.g. $0-1$ and 1-2), including those three who were FISH confirmed to change from HER2 - to HER2 + . Of these 11, seven (64\%) showed some loss of ER (Fig. 3). All of the cases that recurred after finishing tamoxifen were HER2 - in both the primary and recurrent tumour.

\section{Insulin-like growth factor receptor 1}

IGF1R data for paired primary and recurrent tumours was available for 49 cases. There was no difference in primary IGF1R expression in tumours that went on to recur as ER + or ER - (Table 4). There was a significant reduction of IGF1R in recurrent tumours $(P<0.0001)$. This was true in both the group that retained ER + status $(P<0.0001)$ and that were ER at the time of recurrence $(P=0.004)$. Approximately, $75 \%$ of tumours that recurred as ER + showed a reduction of IGF1R. A case losing IGF1R at recurrence is shown in Fig. 4a and b. Median reduction in IGF1R expression was similar in ER - (Fig. 2d) and ER+ (both low and high ER; Fig. 2e and f) recurrences.
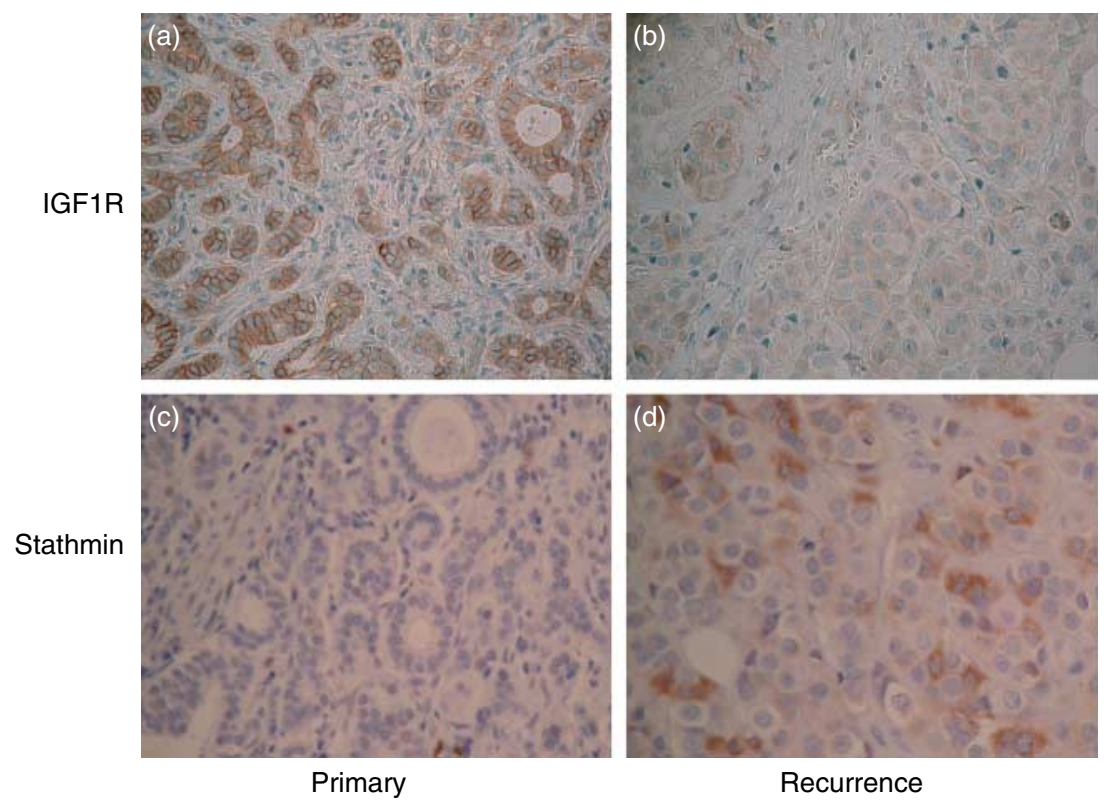

Recurrence

Figure 4 Immunohistochemistry of membrane IGF1R and cytoplasmic stathmin in an ER + primary tumour and the ER + recurrence following tamoxifen treatment. Clear IGF1R membrane staining is observed in the primary (a), which is reduced following tamoxifen treatment and the development of resistance (b). In the same patient, cytoplasmic stathmin staining is absent in the primary (c) and is higher in the recurrence $(d)$, suggesting activation of the PI3K pathway. 
The lack of a significant quantitative relationship between IGF1R and ER levels pretreatment persisted in the recurrence. There was, however, a weak relationship between the differences in ER and IGFIR level between primary and recurrence $(r=0.34 ; P=0.018)$.

In 39 patients recurring on tamoxifen, IGF1R data for paired primary and recurrent tumours was available. IGF1R expression in primary tumours did not differ significantly between those that went on to recur as ER + compared with those that recurred as $\mathrm{ER}-$. As in the complete patient set, there was a significant reduction of IGF1R in the recurrent tumours $(P<0.0001)$. This was true in both the group that retained ER + status $(P<0.0001)$ and that were ER at the time of recurrence $(P=0.004)$. Approximately, $85 \%$ of tumours that recurred as ER + showed a reduction of IGF1R.

\section{Stathmin}

Stathmin levels were higher in primary tumours that recurred as ER - than ER + (Table 4), although this was not significant. The majority of $(59 \%)$ ER + primary cases showed an increase of stathmin at the time of recurrence $(P<0.005$; example Fig. $4 \mathrm{c}$ and $\mathrm{d})$, with both $\mathrm{ER}+$ and $\mathrm{ER}-$ recurrences showing an increase (Fig. 2g-i), although only significantly so in the subgroup of patients with maintained ER positivity $(P=0.004)$. The greatest proportion of patients $(73 \%)$ with increased stathmin was observed in those that had high ER (H-score $\geq 25$ ) recurrent disease (Fig. 2i) compared with those with ER - or ER low recurrences (42 and 45\%, respectively; Fig. $2 \mathrm{~g}$ and h). Cases with increased levels of stathmin at recurrence compared with primary, had a non-significant trend to longer TTR (median 49.0 vs 28.5 months; $P=0.086$ ).

Changes in stathmin and ER were not quantitatively related. There was no correlation between levels of stathmin and IGF1R in primaries, or in their difference of expression, but there was a trend to a weak positive relationship in recurrences $(r=0.28 ; P=0.056)$.

Changes were similar in just those patients who recurred whilst taking tamoxifen. Stathmin levels were higher in primary tumours that recurred as ER - than $\mathrm{ER}+(P=0.054)$ and the majority of $(55 \%) \mathrm{ER}+$ primary cases showed an increase of stathmin at the time of recurrence, The greatest proportion of patients (76\%) with increased stathmin was observed in those with high ER (H-score $\geq 25$ ) compared with ER - or low recurrences (42 and 33\% respectively). Changes in stathmin and ER were not quantitatively related. There was no correlation between levels of stathmin and IGF1R in primaries, or in their difference of expression.

\section{PTEN}

Tumours that remained ER + at recurrence $(n=34)$, showed maintained PTEN expression in $68 \%$ and only $6 \%$ lost PTEN at the time of recurrence. $18 \%$ were PTEN - in the primary and recurrent tumour and a further 9\% acquired PTEN positivity. This was in contrast to those who became ER - $(n=11)$, where $27 \%$ also showed loss of PTEN (Fig. 5). Overall, absence of PTEN occurred in the primary tumour in $27 \%$ of those who retained ER positivity and $36 \%$ who lost ER.

There was no difference in levels of stathmin between PTEN + and PTEN - tumours in either primary or recurrent tumours.

\section{PIK3CA hotspot mutations}

Twenty-one pairs of tumours, including ER - primary samples, were sequenced for three hotspot mutations, in exons 9 and 20. A mutation was identified in five

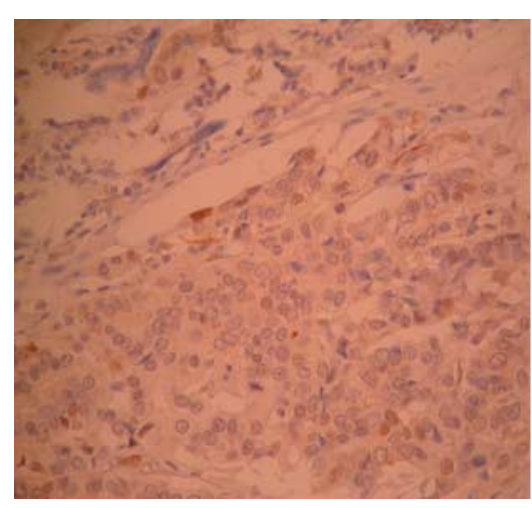

Primary

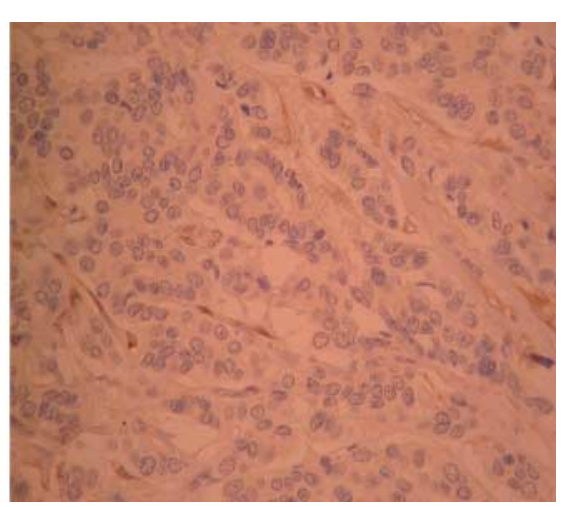

Recurrence

Figure 5 Immunohistochemistry of PTEN in an ER + primary and matched ER - recurrence following tamoxifen treatment. PTEN loss is clearly observed in the recurrent lesion. 
cases and in all five the mutation occurred in both the primary and recurrent sample. The E545K mutation in exon 9 was observed in one patient with an ER + to ER - resistant tumour, the H1047R mutation in exon 20 in two ER + to ER + tumours and one ER - to ER - tumour and the H1047L mutation in exon 20 was observed in one tumour that acquired ER positivity. Overall, the hotspot mutation rate was $3 / 14$ of ER+ tumours, or $21 \%$.

\section{Summary}

Many changes in biomarker expression occur in the acquisition of tamoxifen resistance. To achieve an overview of the data we conducted hierarchical clustering analyses and created heatmaps based on the pretreatment expression of the seven parameters (Fig. 6a). This clustering is then applied to the recurrent samples and the differences between the pretreatment and recurrent samples in Fig. $6 \mathrm{~b}$ and c. HER2 and PTEN status appear to dominate the separation of tumours before treatment, with there being near absolute separation of PTEN-positive from negative tumours. The HER2-positive tumours cluster together within the PTEN-positive and PTEN-negative clusters. However, the pretreatment clustering does not impose a clear clustering of the recurrent phenotypes.

\section{Discussion}

Resistance to tamoxifen occurs clinically in $\sim 40 \%$ of adjuvantly treated patients and almost all metastatic patients. Despite the increasing use of aromatase inhibitors, tamoxifen remains an important therapeutic option, both for pre-menopausal women and as a sequential regimen with aromatase inhibitors. There have been relatively few clinical reports of changes occurring in the acquisition of tamoxifen resistance; here, we describe a set of matched primary and tamoxifen-resistant recurrences. Differences in expression of the biomarkers are substantial but complex. A number of changes occur that are consistent with concepts of tamoxifen resistance, but these vary greatly between patients. The clustering based on pretreatment samples showed dominance

(a)
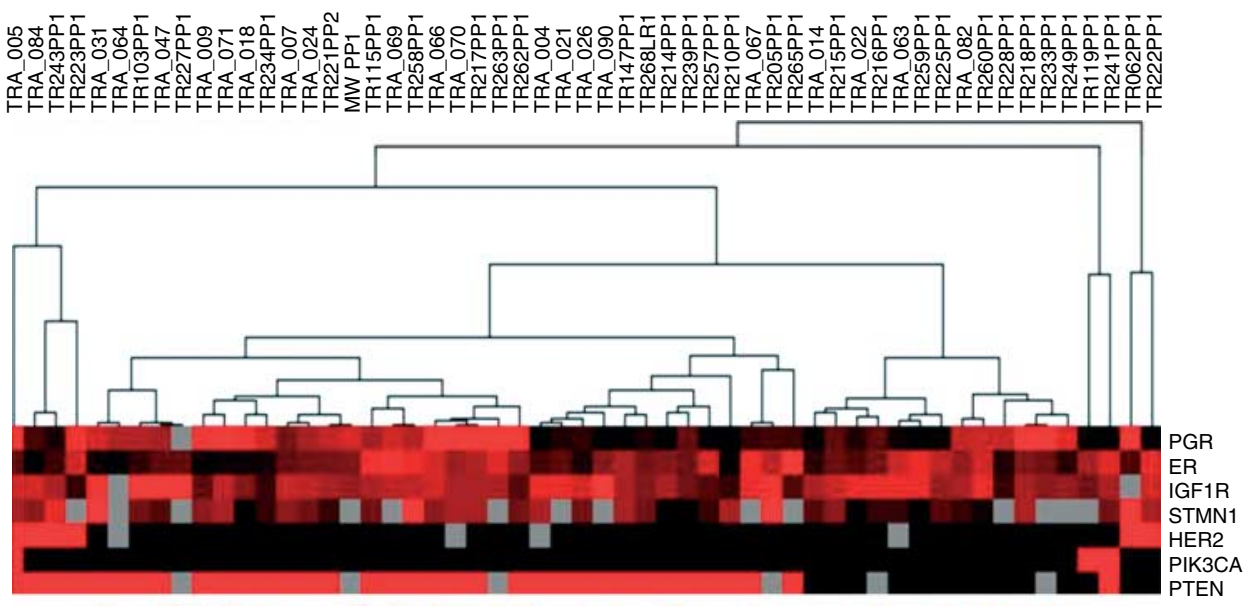

(b)

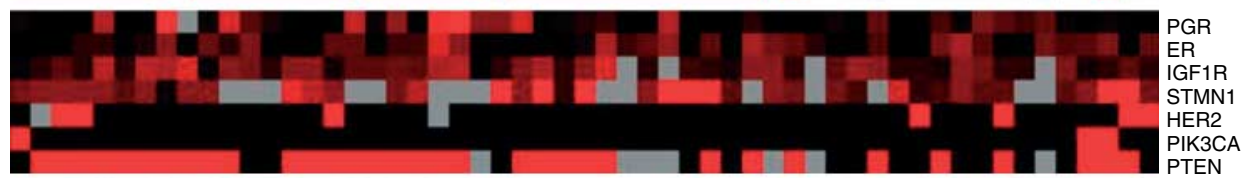

(c)

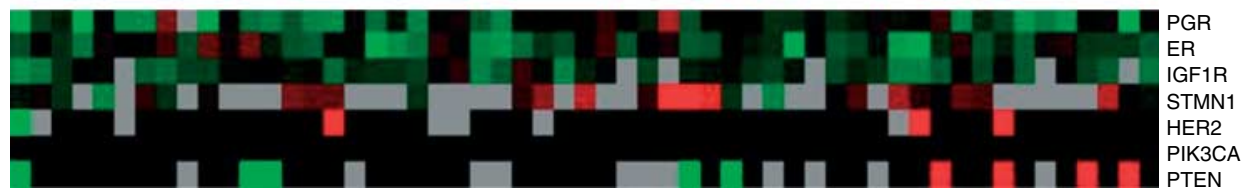

Figure 6 Heatmaps of $55 \mathrm{ER}+$ patients with excision biopsies pre- and post-tamoxifen therapy. (a) Primary tumours were clustered based on the expression values of the seven biomarkers (scaled data). Only black and red colours are observed, as the data has not been centred, i.e. this heatmap represents absolute expression values after data scaling as described, where black is low expression, red high and grey indicates missing data. (b) Scaled data for the recurrent tumour is shown below the corresponding primary; (c) the difference between primary and recurrent expression is shown (scaled data), with green showing reduced expression, red increased expression, grey is missing data and black is no change. 
of PTEN and HER2 status in this marker set but it is possible that this largely reflects the dichotomous nature of the data on these two markers. The strong pretreatment patterns were not persistent through to the recurrent lesions indicating that pretreatment phenotype does not strongly predict for on phenotype at recurrence.

ER levels were significantly reduced, and sometimes lost altogether in tamoxifen-resistant recurrences. While reduced PgR might be expected following tamoxifen treatment because of its antioestrogenic activity, there is little evidence that this occurs. Rather, presumably due to a substantial agonist effect of tamoxifen on this gene's expression, $\mathrm{PgR}$ expression is increased in many ER + breast tumours shortly after starting tamoxifen treatment (Howell et al. 1987). Also, in patients treated with tamoxifen as primary medical therapy who acquired resistance, there was little loss of PgR (Johnston et al. 1995). The suppression of $\operatorname{PgR}$ confirmed in this study and previously reported in the adjuvant tamoxifen-resistant setting (Johnston et al. 1995), may therefore be explained by loss of ER functionality. This is supported by the greater loss of $\mathrm{PgR}$ shown in the tumours with low or negative ER recurrences (Fig. 2), as well as the suppression of oestrogen-regulated IGF1R.

In our previous report (Gutierrez et al. 2005), we showed a positive association of ER status with PgR in the primary setting, which was lost at recurrence and this was confirmed here. In this updated set, looking at only ER + primary tumours, no quantitative relationship with PgR was observed in primary tumours, but was present at resistance, probably due largely to the ER - recurrences, again supporting the above hypothesis.

Only $10 \%$ of ER + tamoxifen-resistant patients were HER $2+$ initially and only $6 \%$ acquired HER 2 at the time of recurrence. No tumours were found to acquire HER 2 positivity in the recurrence beyond the three cases previously reported (Gutierrez et al. 2005), confirming that absolute gain of HER2 is an uncommon occurrence. However, a further eight cases showed some increase of HER2 protein. ER was reduced in the majority of these cases (64\%).

The data presented here show for the first time that IGF1R is reduced in the recurrence of many tamoxifenresistant patients. It has been reported that tumours showing primary resistance to tamoxifen are frequently IGF1R poor while those that respond, IGF1R rich (Gee et al. 2005). Tamoxifen-resistant cells also have a down-regulation of IGF1R compared with parental cells, although phosphorylated levels remain the same (Knowlden et al. 2005). The suppression of IGF1R therefore appears to be a consistent feature of the tamoxifen-resistant phenotype. Whilst the loss of IGF1R was weakly associated with loss of ER, there is evidence that this is an independent event as even tumours that showed no significant loss of ER, had a significant loss of IGF1R. A positive association of IGF1R has been observed previously with ER and PgR (Pekonen et al. 1988, Peyrat et al. 1988, Gee et al. 2005); however, others (including ourselves in this series) have not observed the relationship with PgR (Papa et al. 1993). Time to progression was significantly increased for IGF1R rich patients and there was longer TTR for patients whose recurrence showed an increase of IGF1R. The data indicating lower expression of IGF1R in tamoxifen resistance are relevant to the targeting of the large number of IGF1R kinase inhibitor and antibodies in clinical development.

Stathmin has been identified as an immunohistochemical marker of activation of the PI3K pathway and lack of PTEN (Saal et al. 2007). However, the relationship of stathmin with PTEN expression was not observed in this cohort, with no difference in stathmin levels between PTEN + and PTEN tumours, suggesting that taken alone, stathmin may not be a good marker of PTEN. No relationship between ER and stathmin in ER + primary cases was observed in this study confirming previous reports (Golouh et al. 2008). A negative relationship between ER status and stathmin was observed consistent with another study, including cell lines (Brattsand 2000). A negative relationship with ER has also been shown to hold at the stathmin mRNA level (Curmi et al. 2000).

A significant increase in stathmin expression occurred in the tamoxifen-resistant recurrence of $\mathrm{ER}+$ primary tumours, suggesting activation of the PI3K pathway. Although stathmin levels are higher in ER - primary tumours, interestingly there was no significant increase of stathmin in patients developing an ER - recurrence, but this was a small subgroup in our study. Furthermore, in primary tumours there was no relationship of stathmin with IGF1R, despite this putative common association with an activated PI3K pathway. A positive association was observed at recurrence, suggesting that some coalescence of their activities may be acquired. Golouh et al. (2008) reported that high stathmin staining intensity in the primary tumour was associated with shorter diseasefree survival in tamoxifen-treated ER + patients. Stathmin has also been found to be overexpressed in the presence of mutant Tp53 (Alli et al. 2007), a feature associated with poor response to tamoxifen (Berns et al. 2000). Stathmin overexpression has been associated with reduced sensitivity to 
chemotherapeutic drugs (Alli et al. 2002). Despite a number of patients having received chemotherapy in addition to tamoxifen in this study, none were treated with a regimen that targeted microtubules.

Further evidence consistent with PI3K activation with acquisition of tamoxifen resistance comes from lower PgR levels in tamoxifen-resistant recurrences. IGF1 mediated decreases of PgR protein and mRNA levels via an inhibition of transcription have been demonstrated in breast cancer (Cui et al. 2003), with the PI3K/Akt/mTOR pathway being specifically implicated. The reduction of $\mathrm{PgR}$ levels in this series was found to be independent of ER activity. Furthermore, PTEN loss (implicated in this study by increased stathmin) and reduced $\mathrm{PgR}$ have been observed both in vitro (Miller et al. 2009) and in vivo (Saal et al. 2005). However, our data, although limited in number, suggest that PTEN loss contributes to only a small proportion of tamoxifen-resistant tumours, with the majority of ER + recurrent tumours maintaining PTEN positivity. Less than a quarter of patients that recurred on tamoxifen showed a PIK3CA mutation in the primary tumour; we found no evidence of this frequency increasing at recurrence.

Immunohistochemistry is a useful tool to assess these markers, particularly in the tissue microarray setting as many samples can be stained at once. However, not all markers can be well represented in a tissue microarray (TMA) format and for this reason the heterogeneous staining PgR was performed on whole sections in this study. The use of ER, PgR and HER2 is well documented and while the research community is increasingly becoming aware of the instability of certain markers in stored fixed biopsies over time, we can be reassured in this study by the fact that most markers showed reduced levels in the recurrent (more recent) sample.

In summary, we have confirmed the loss of ER and $\mathrm{PgR}$ in tamoxifen-resistant recurrences and shown that acquisition of HER2 positivity is an uncommon event. There is no evidence for increases in IGF1R or in mutations in PIK3CA, but increases in stathmin levels, and infrequent loss of PTEN indicate activation of the PI3K pathway in some tamoxifen-resistant breast tumours. It is unlikely that a single mechanism of resistance exists; molecular characterisation of individual recurrent lesions is needed to select the most appropriate treatment in progressive advanced disease.

\section{Supplementary data}

This is linked to the online version of the paper at http://dx. doi.org/10.1530/ERC-10-0046

\section{Declaration of interest}

The authors declare that there is no conflict of interest that could be perceived as prejudicing the impartiality of the research reported.

\section{Funding}

This research did not receive any specific grant from any funding agency in the public, commercial or not-for-profit sector.

\section{Acknowledgements}

We wish to acknowledge funding from Breakthrough Breast Cancer and NHS funding to the NIHR Biomedical Research Centre. We thank Margaret Hills for performing FISH analysis and Eric Ward for PTEN staining.

\section{References}

Alli E, Bash-Babula J, Yang JM \& Hait WN 2002 Effect of stathmin on the sensitivity to antimicrotubule drugs in human breast cancer. Cancer Research 62 6864-6869.

Alli E, Yang JM \& Hait WN 2007 Silencing of stathmin induces tumor-suppressor function in breast cancer cell lines harboring mutant p53. Oncogene 26 1003-1012. (doi:10.1038/sj.onc.1209864)

Berns EM, Foekens JA, Vossen R, Look MP, Devilee P, Henzen-Logmans SC, van Staveren IL, van Putten WL, Inganäs M, Meijer-van Gelder ME et al. 2000 Complete sequencing of TP53 predicts poor response to systemic therapy of advanced breast cancer. Cancer Research 60 2155-2162.

Brattsand G 2000 Correlation of oncoprotein 18/stathmin expression in human breast cancer with established prognostic factors. British Journal of Cancer 83 311-318. (doi:10.1054/bjoc.2000.1264)

Bunone G, Briand PA, Miksicek RJ \& Picard D 1996 Activation of the unliganded estrogen receptor by EGF involves the MAP kinase pathway and direct phosphorylation. EMBO Journal 15 2174-2183.

Chan TW, Pollak M \& Huynh H 2001 Inhibition of insulinlike growth factor signaling pathways in mammary gland by pure antiestrogen ICI 182780 . Clinical Cancer Research 7 2545-2554.

Cui X, Zhang P, Deng W, Oesterreich S, Lu Y, Mills GB \& Lee AV 2003 Insulin-like growth factor-I inhibits progesterone receptor expression in breast cancer cells via the phosphatidylinositol 3-kinase/Akt/mammalian target of rapamycin pathway: progesterone receptor as a potential indicator of growth factor activity in breast cancer. Molecular Endocrinology 17 575-588. (doi:10. 1210/me.2002-0318)

Curmi PA, Nogués C, Lachkar S, Carelle N, Gonthier MP, Sobel A, Lidereau R \& Biéche I 2000 Overexpression 
of stathmin in breast carcinomas points out to highly proliferative tumours. British Journal of Cancer $\mathbf{8 2}$ 142-150. (doi:10.1054/bjoc.1999.0891)

Cuzick J, Forbes JF, Sestak I, Cawthorn S, Hamed H, Holli K \& Howell A 2007 Long-term results of tamoxifen prophylaxis for breast cancer - 96-month follow-up of the randomized IBIS-I trial. Journal of National Cancer Institute 99 272-282. (doi:10.1093/jnci/djk049)

Detre S, SaclaniJotti G \& Dowsett M 1995 A quickscore method for immunohistochemical semiquantitation: validation for oestrogen receptor in breast carcinomas. Journal of Clinical Pathology 48 876-878. (doi:10.1136/ jcp.48.9.876)

Dowsett M 2006 Estrogen receptor: methodology matters. Journal of Clinical Oncology 24 5626-5628. (doi:10. 1200/JCO.2006.08.3485)

Dowsett M, Allred C, Knox J, Quinn E, Salter J, Wale C, Cuzick J, Houghton J, Williams N, Mallon E et al. 2008 Relationship between quantitative estrogen and progesterone receptor expression and human epidermal growth factor receptor 2 (HER-2) status with recurrence in the Arimidex, Tamoxifen, Alone or in Combination trial. Journal of Clinical Oncology 26 1059-1065. (doi:10.1200/JCO.2007.12.9437)

Dupont J \& Le Roith D 2001 Insulin-like growth factor 1 and oestradiol promote cell proliferation of MCF-7 breast cancer cells: new insights into their synergistic effects. Molecular Pathology 54 149-154. (doi:10.1136/mp.54.3.149)

Early Breast Cancer Trialists' Collaborative Group 1988 Effects of adjuvant tamoxifen and of cytotoxic therapy on mortality in early breast cancer. An overview of 61 randomized trials among 28896 women. New England Journal of Medicine 319 1681-1692. (doi:10.1056/ NEJM198812293192601)

Early Breast Cancer Trialists' Collaborative Group 1998 Tamoxifen for early breast cancer: an overview of the randomised trials. Lancet 351 1451-1467. (doi:10.1016/ S0140-6736(97)11423-4)

Frogne T, Jepsen JS, Larsen SS, Fog CK, Brockdorff BL \& Lykkesfeldt AE 2005 Antiestrogen-resistant human breast cancer cells require activated protein kinase B/Akt for growth. Endocrine-Related Cancer 12 599-614. (doi:10. 1677/erc.1.00946)

Gee JM, Robertson JF, Gutteridge E, Ellis IO, Pinder SE, Rubini M \& Nicholson RI 2005 Epidermal growth factor receptor/HER2/insulin-like growth factor receptor signalling and oestrogen receptor activity in clinical breast cancer. Endocrine-Related Cancer 12 (Suppl 1) S99-S111. (doi:10.1677/erc.1.01005)

Golouh R, Cufer T, Sadikov A, Nussdorfer P, Usher PA, Brünner N, Schmitt M, Lesche R, Maier S, Timmermans $\mathrm{M}$ et al. 2008 The prognostic value of stathmin-1, S100A2, and SYK proteins in ER-positive primary breast cancer patients treated with adjuvant tamoxifen monotherapy: an immunohistochemical study. Breast Cancer Research and Treatment 110 317-326. (doi:10.1007/ s10549-007-9724-3)
Gutierrez MC, Detre S, Johnston S, Mohsin SK, Shou J, Allred DC, Schiff R, Osborne CK \& Dowsett M 2005 Molecular changes in tamoxifen-resistant breast cancer: relationship between estrogen receptor, HER-2, and p38 mitogen-activated protein kinase. Journal of Clinical Oncology 23 2469-2476. (doi:10.1200/JCO. 2005.01.172)

Guvakova MA \& Surmacz E 1997 Tamoxifen interferes with the insulin-like growth factor I receptor (IGF-IR) signaling pathway in breast cancer cells. Cancer Research 57 2606-2610.

Howell A, Harland RN, Barnes DM, Baildam AD, Wilkinson MJS, Hayward E, Swindell R \& Sellwood RA 1987 Endocrine therapy for advanced carcinoma of the breast: relationship between the effect of tamoxifen upon concentrations of progesterone receptor and subsequent response to treatment. Cancer Research 47 300-304.

Hutcheson IR, Knowlden JM, Madden TA, Barrow D, Gee JM, Wakeling AE \& Nicholson RI 2003 Oestrogen receptor-mediated modulation of the EGFR/MAPK pathway in tamoxifen-resistant MCF-7 cells. Breast Cancer Research and Treatment $\mathbf{8 1}$ 81-93. (doi:10.1023/A:1025484908380)

Johnston SR, Saccani-Jotti G, Smith IE, Salter J, Newby J, Coppen M, Ebbs SR \& Dowsett M 1995 Changes in estrogen receptor, progesterone receptor, and $\mathrm{pS} 2$ expression in tamoxifen-resistant human breast cancer. Cancer Research 55 3331-3338.

Kalinsky K, Jacks LM, Heguy A, Patil S, Drobnjak M, Bhanot UK, Hedvat CV, Traina TA, Solit D, Gerald W et al. 2009 PIK3CA mutation associates with improved outcome in breast cancer. Clinical Cancer Research 15 5049-5059. (doi:10.1158/1078-0432.CCR-09-0632)

Knowlden JM, Hutcheson IR, Barrow D, Gee JMW \& Nicholson RI 2005 Insulin-like growth factor-I receptor signaling in tamoxifen-resistant breast cancer: a supporting role to the epidermal growth factor receptor.

Endocrinology 146 4609-4618. (doi:10.1210/en.20050247)

Law JH, Habibi G, Hu K, Masoudi H, Wang MYC, Stratford AL, Park E, Gee JMW, Finlay P, Jones HE et al. 2008 Phosphorylated insulin-like growth factor-i/insulin receptor is present in all breast cancer subtypes and is related to poor survival. Cancer Research 68 10238-10246. (doi:10.1158/0008-5472.CAN-08-2755)

Massarweh S, Osborne CK, Creighton CJ, Qin L, Tsimelzon A, Huang S, Weiss H, Rimawi M \& Schiff R 2008 Tamoxifen resistance in breast tumors is driven by growth factor receptor signaling with repression of classic estrogen receptor genomic function. Cancer Research $\mathbf{6 8}$ 826-833. (doi:10.1158/0008-5472.CAN-07-2707)

Miller TW, Perez-Torres M, Narasanna A, Guix M, Stâl O, Pérez-Tenorio G, Gonzalez-Angulo AM, Hennessy BT, Mills GB, Kennedy JP et al. 2009 Loss of phosphatase and tensin homologue deleted on chromosome 10 engages ErbB3 and insulin-like growth factor-I receptor signaling 
to promote antiestrogen resistance in breast cancer. Cancer Research 69 4192-4201. (doi:10.1158/00085472.CAN-09-0042)

Nicholson RI, Hutcheson IR, Britton D, Knowlden JM, Jones HE, Harper ME, Hiscox SE, Barrow D \& Gee JM 2005 Growth factor signalling networks in breast cancer and resistance to endocrine agents: new therapeutic strategies. Journal of Steroid Biochemistry and Molecular Biology 93 257-262. (doi:10.1016/j.jsbmb.2004.12.006)

Pancholi S, Lykkesfeldt AE, Hilmi C, Banerjee S, Leary A, Drury S, Johnston S, Dowsett M \& Martin LA 2008 ERBB2 influences the subcellular localization of the estrogen receptor in tamoxifen-resistant MCF-7 cells leading to the activation of AKT and RPS6KA2. Endocrine-Related Cancer 15 985-1002. (doi:10.1677/ ERC-07-0240)

Papa V, Gliozzo B, Clark GM, McGuire WL, Moore D, Fujita-Yamaguchi Y, Vigneri R, Goldfine ID \& Pezzino V 1993 Insulin-like growth factor-I receptors are overexpressed and predict a low risk in human breast cancer. Cancer Research 53 3736-3740.

Pekonen F, Partanen S, Mäkinen T \& Rutanen EM 1988 Receptors for epidermal growth factor and insulin-like growth factor I and their relation to steroid receptors in human breast cancer. Cancer Research 48 1343-1347.

Peyrat JP, Bonneterre J, Beuscart R, Djiane J \& Demaille A 1988 Insulin-like growth factor 1 receptors in human breast cancer and their relation to estradiol and progesterone receptors. Cancer Research 48 6429-6433.

Quinn E, Salter J \& Hills M 2008 Concordance between tissue microarray and whole tissue sections for ER expression and PgR and HER-2 Status: a pilot study for the Trans-ATAC trial. European Journal of Cancer 140 (Suppl 6) abstract 311.

Riedemann J \& Macaulay VM 2006 IGF1R signalling and its inhibition. Endocrine-Related Cancer 13 (Suppl 1) S33-S43. (doi:10.1677/erc.1.01280)
Saal LH, Holm K, Maurer M, Memeo L, Su T, Wang X, Yu JS, Malmström PO, Mansukhani M, Enoksson J et al. 2005 PIK3CA mutations correlate with hormone receptors, node metastasis, and ERBB2, and are mutually exclusive with PTEN loss in human breast carcinoma. Cancer Research 65 2554-2559. (doi:10.1158/00085472-CAN-04-3913)

Saal LH, Johansson P, olm K, Gruvberger-Saal SK, She QB, Maurer M, Koujak S, Ferrando AA, Malmström P, Memeo L et al. 2007 Poor prognosis in carcinoma is associated with a gene expression signature of aberrant PTEN tumor suppressor pathway activity. PNAS 104 7564-7569. (doi:10.1073/pnas.0702507104)

Sakr RA, Barbashina V, Morrogh M, Chandarlapaty S, Andrade VP, Arroyo CD, Olvera N \& King TA 2010 Protocol for PTEN expression by immunohistochemistry in formalin-fixed paraffin-embedded human breast carcinoma. Applied Immunohistochemistry \& Molecular Morphology 18 371-374. (doi:10.1097/PAI.0b013e 3181d50bd5)

Stemke-Hale K, Gonzalez-Angulo AM, Lluch A, Neve RM, Kuo WL, Davies M, Carey M, Hu Z, Guan Y, Sahin A et al. 2008 An integrative genomic and proteomic analysis of PIK3CA, PTEN, and AKT mutations in breast cancer. Cancer Research 68 6084-6091. (doi:10.1158/00085472.CAN-07-6854)

Stewart AJ, Johnson MD, May FE \& Westley BR 1990 Role of insulin-like growth factors and the type I insulin-like growth factor receptor in the estrogen-stimulated proliferation of human breast cancer cells. Journal of Biological Chemistry $26521172-21178$.

Received in final form 29 April 2011

Accepted 5 July 2011

Made available online as an Accepted Preprint 6 July 2011 